\title{
DISCREPANCIES BETWEEN SPECTRAL DOMAIN OPTICAL COHERENCE TOMOGRAPHY
} AND FLUORESCEIN ANGIOGRAPHY IN DETECTING UVEITIC MACULAR EDEMA

Vesela T. Mitkova-Hristova ${ }^{1,2 *}$, Marieta I. Konareva-Kostianeva ${ }^{1,2}$, Arsenia M. Balian $^{1,2}$, Nina S. Stoyanova ${ }^{1,2}$, Maria A. Semerdzhieva ${ }^{3}$

${ }^{1}$ Department of Ophthalmology, Faculty of Medicine, Medical University - Plovdiv, ${ }^{2}$ University Clinic of Ophthalmology, St. George University Hospital, Plovdiv, ${ }^{3}$ Department of Health Care Management, Faculty of Public Health, Medical University, Plovdiv, Bulgaria

\section{НЕСООТВЕТСТВИЕ МЕЖДУ СПЕКТРАЛ-ДОМЕН ОПТИЧЕСКОЙ КОГЕРЕНТНОЙ ТОМОГРАФИЕЙ И ФЛЮОРЕСЦЕИНОВОЙ АНГИОГРАФИЕЙ ПРИ ДИАГНОСТИКЕ ОТЁКА МАКУЛЫ ГЛАЗ ПРИ УВЕИТАХ}

Весела Т. Миткова-Христова ${ }^{1,2 *}$ Мариета И. Конарева-Костянева ${ }^{1,2}$, Арсения М. Балиян ${ }^{1,2}$, Нина С. Стоянова ${ }^{1,2}$, Мария А. Семерджиева ${ }^{3}$

${ }^{1}$ Кафедра глазных болезней, Факультет медииины, ${ }^{2}$ Клиника офтальмологии, УМБАЛ „Св. Георги” ЕАД, ${ }^{3}$ Кафедра управления здравоохранением, Факультет общественного здоровья, Медииинский университет, Пловдив, Болгария

\begin{abstract}
Aıм: To compare spectral-domain optical coherence tomography (SD-OCT) with fluorescein angiography (FA) in detecting macular edema in patients with uveitis and analyse discrepancies in the findings obtained by the two methods. Methods: The study included 133 eyes from 117 patients with uveitis that had SD-OCT (RTVue-100/ Optovue) and FA (Topcon TRC 50DX) scans performed to detect or rule out macular edema. RESULTs: Macular edema was found in 57 (42.9\%) of the 133 surveyed eyes. In 37 eyes (27.8\%) macular edema was confirmed by both imaging methods. In 17 eyes $(12.8 \%)$ macular edema was detected on SD-OCT but not on FA;in 15 eyes of these the edema was diffuse, and in 2 eyes - serous retinal detachment was verified in the macular area. Focal macular edema was detected on FA in three eyes (2.3\%) in which SD-OCT showed normal finding. In 76 eyes (57.1\%) no pathological changes in the macula were observed on both SD-OCT and FA. Kappa coefficient was 0.675 at $\mathrm{p}<0.001$. The agreement rate between the two methods calculated using Kendall's tau-b was 0.693 at $\mathrm{p}<0.001$. ConcLusion: Fluorescein angiography and spectral domain optical coherence tomography are highly sensitive methods used in detecting macular edema in patients with uveitis, but they might fail to be efficient in this if used independently. Optical coherence tomography is a more informative method, especially in diagnosing diffuse macular edema.
\end{abstract}

Key words: macular edema, uveitis, optical coherence tomography, fluorescein angiography

Folia Medica 2015;57(3\&4):207-215 Copyright (C) 2015 Medical University, Plovdiv

\section{РЕЗЮМЕ}

Цель: Сравнение возможностей спектрал-домен оптической когерентной томографии и флюоресцеиновой ангиографии при диагностике отёка макулы у пациентов с увеитом, с анализом несоответствий в находках, полученных в результате применения обоих методов. МАтЕРиАл и методы: Объектом исследования являются 133 глаза (117 пациентов), страдающих увеитом, в отношении которых была проведена спектралдомен оптическая когерентная томография (RTVue-100/Optovue) и флюоресцеиновая ангиография (Торcon TRC 50DX) для установления или исключения диагноза отёка макулы. Результаты: Отёк макулы установлен в 57 (42.9\%) из исследованных 133 глаз. В 37 из случаев (27.8\%) отёк макулы установлен обоими образно-дианостическими методами. В 17 из случаев (12.8\%) отёк макулы зарегистрирован только при помощи оптической когерентной томографии, при этом в 15 из них отёк является диффузным, а в двух глазах наблюдается серьёзная отслойка нейроэпителия в области макулы. Фокальный отёк макулы установлен при помощи флюоресцеиновой ангиографии в 3 из случаев (2.3\%), в отношении которых оптическая когерентная томография установила нормальную находку. В 76 из случаев (57.1\%) не установлены патологические изменения макулы с использованием обоих методов. Мера согласованности (Капа) составляет 0.675 , при $\mathrm{p}<0.001$. Коэффициент корреляции между двумя методами, установленный посредством метода Kendall's tau-b составляет 0.693, при p < 0.001. Вывод: Флюоресцеиновая ангиогарфия и спектрал-домен оптическая когерентная томография являются высокочувствительными методами

Article's history: Received: 30 Aug 2015; Received in a revised form: 15 Sept 2015; Accepted: 10 Dec 2015

*Correspondence and reprint request to:V. Mitkova-Hristova, Department of Ophthalmology, Faculty of Medicine, Medical University, Plovdiv; E-mail: vesela_mitkova@abv.bg; Tel.: +359 888765567 
при установлении отёка макулы при пациентах с увеитами, но вероятна возможность пропуска при самостоятельном применении каждого из них. Оптическая когерентная томография является наиболее информативным методом, особенно при диагностике диффузного отёка макулы.

Ключевые слова: отёкмакуль, увеит, оптическая когерентная томография, флюоресцеиновая ангиография

Folia Medica 2015;57(3\&4):207-215

(C) 2015 Все права защищены. Медицинский университет, Пловдив

\section{INTRODUCTION}

Macular edema (ME) is one of the leading causes of decreased vision in a number of eye diseases such as inflammatory disorders, vascular retinal disorders, vascular disorders of the choroid, traction maculopathy, retinal detachment, intraocular tumors, etc. ${ }^{1,2}$ Although it is not specific, ME is a typical complication of uveitis; it may be responsible for permanent visual impairment in $8.5 \%$ of all cases. ${ }^{3}$ It is found in all types of uveitis, its incidence depending on the anatomical position of inflammation. Most often it affects the vitreous body ${ }^{4}$, but can also be detected in anterior uveitis $(20-26 \%)$, posterior uveitis $(20 \%)$ and panuveitis $(35 \%) .^{5}$

Finding ways of making an accurate diagnosis of ME is a major priority of research in this field. Until recently, one of the most common methods of detecting uveitis in clinical practice was fluorescein angiography (FA). FA can help in investigating the blood retinal barrier and find how severe the retinal vesicles, the choroid and the optical nerve have been affected. It can identify the anatomical location and pattern of vascular leakage ${ }^{1,6-9}$, but can give only a qualitative assessment of the edema. Moreover, the size and area of vascular leakage do not have a significant correlation with visual acuity. ${ }^{10-12}$ Although this method is very useful in making a final diagnosis, FA is an invasive procedure and the interpretation of the results is potentially a subjective assessment. ${ }^{6}$

In recent years, ophthalmologic practice has made increasing use of optical coherence tomography (OCT). This is a relatively new, objective, reliable method for studying and diagnosing macular pathology. ${ }^{11,13-15}$ OCT can show not only presence of fluid in the retina, but also its anatomical distribution. The method allows a quantitative estimate of retinal thickness and volume. ${ }^{16}$ The latest generation of spectral OCT devices have high axial resolution $(<5 \mu \mathrm{m})$, which allows visualisation of different retinal layers and early diagnosis of macular edema. ${ }^{9}$ The method is non-invasive, non-contact, it is easily executable, allowing the detection of uveitic ME in the course of the therapy. ${ }^{1,17}$

\section{AIM}

To compare spectral domain optical coherence tomography and fluorescein angiography in diagnosing macular edema in patients with uveitis and analyse the discrepancies in the findings obtained by the two methods.

\section{PATIENTS AND METHODS}

The present prospective study included 117 patients (133 eyes) with uveitis, treated in the University Eye Clinic in Plovdiv, Bulgaria between January 2010 and April 2012. The patients ( $\geq 20$ years old) had been diagnosed with uveitis with evidence of an active inflammatory disease. Exclusion criteria: inflammatory diseases involving the ocular appendages and/or the eye layers and internal structures together with the uveal tract; patients with a history of uveitis inactive at the time of study; other diseases involving the retina and choroidea that affect macular thickness; uveitis secondary to sustained trauma, surgical intervention or malignant process;reduced transparency of eye structures that makes it impossible to obtain a quality OCT imaging and/or performing FA; age under 20 years (due to the small number of cases, patients under 20 years of age were excluded from the study).

The OCT study of ME was done using RTVue 100 (Optovue, Fremont CA, US), which is a frequency (Fourier) domain optical coherence tomograph. We used version 4.0 of the software. To obtain data about the normal ranges for the OCT used in the study we recruited 160 healthy volunteers (160 eyes) aged $\geq 20$ years, with no history of uveitis or other ocular diseases.

For the patients with uveitis the OCT scanning was performed after medicamentous mydriasis. The control group was examined without preliminary preparation. The following scan protocols were used in the study: MM6, EMM5 and 3D Reference (the latter is mandatory when EMM5 scanning is opted for), and the data obtained by the scans were analysed qualitatively and quantitatively. The parameters used for the analysis of retinal thickness were plotted on the chart with the nine fields according to Early Treatment Diabetic Retinopathy 
Study (ETDRS). The chart includes a central circle $1 \mathrm{~mm}$ of diameter on which the measured thickness is defined as central foveal thickness (CFT) and two peripheral rings, which are divided into four quadrants (nasal, upper, temporal and lower). The inner ring has a radius of $1-3 \mathrm{~mm}$ and includes the parafoveal area. The outer ring, corresponding to the perifoveal area, has a radius of 3 to $5 \mathrm{~mm}$ for the EMM5 scan protocol and from 3 to $6 \mathrm{~mm}$ for the MM6 scan protocol. The thickness at the central fixation point (CFP) and in the nine fields was measured automatically which renders the data attached with digital and color coding. Some OCT devices automatically calculate the total macular thickness (TMT), but such analysis does not feature in RTVue. The TMT in the study was calculated as the sum of all measurements taken in the nine quadrants, using the following formula: $1 / 36$ (CFT) $+1 / 18$ (the sum of the inner four quadrants) + $3 / 16$ (the sum of the outer four quadrants). ${ }^{18,19}$

We used here the OCT classification which considers three basic ME patterns: diffuse ME (DME), cystoid ME (CME) and serous detachment (SD) of the neuroepithelium from the retinal pigment epithelium (RPE). Accordingly, the eyes with uveitis were divided into four groups: normal macular architectonic - no ME, with DME, CME and SD.

To detect early DME in uveitis we used the modified criteria of Hee $(1998)^{20}$ and Massin $(2002)^{21}$ for retinal thickness that exceeds the mean thickness for healthy eyes by over 2 XSD ( $>$ mean $\pm 2 \times S D)$. This was used for three indicators: CFP, CFT (zone 1 in ETDRS) and TMT. Two of the scan protocols we used to examine the controls gave different distribution of the retinal thickness in the inner quadrants. For this reason we used TMT as a third, additional criterion.

In the DME group we had eyes with diffuse macular thickening, loss of the normal segmentation of the retina, smoothening of the foveal depression, where the macular thickness met the criteria we set above, and in the CME group we had eyes with distinctly outlined hyporeflective, cystoid spaces on the OCT scans, single or simultaneously combined with serous detachment of the neuroepithelium. In another group we placed the eyes that had only serous detachment of the neuroepithelium in the macular area. The eyes which were seen on the OCT scans as having serous detachment combined with cystoid macular edema were included in the CME group to facilitate the comparison with FA results.
The fluorescein angiography was performed using digital fundus camera Topcon TRC-50DX (Topcon Europe Medical B.V.) after complete medicamentous mydriasis. The angiographic images were acquired using standard methods as required by the University of Wisconsin-Madison Fundus Photograph Reading Center, with a modified standard protocol scanning 7 fields in the ocular fundus being used more frequently. ${ }^{22}$ The images were taken at the size of the field $50^{\circ}$, thus enabling a panoramic survey of the sector on the fundus. For the fluorescein angiography we used $5 \mathrm{ml}$ of $5 \%$ aqueous solution of the sodium salt of fluorescein administered intravenously in the cubital vein for 5-6 seconds. To compare the results with SD-OCT scans we used the last images $5-10$ minutes in the tissue phase of FA in field No2 with the macula as center.

Depending on the FA findings in the macula, the studied eyes were allocated into four groups: without ME, with DME, with CME, and with SD of neuroepithelium from RPE. The second group in FA, eyes with DME, included also eyes with focal edema.

FA, and the OCT scanning were mostly performed consecutively in the same day (the rest of the scans were done at an interval of 2-3 days).

All study subjects were Caucasian.

Statistical analysis was performed using SPSS v. 17.0. The battery of analyses included: descriptive analysis - to describe the results presented as means plus standard deviation (mean $\pm \mathrm{SD}$ ); the Kolmogorov-Smirnov test - to determine the distribution type of the quantitative indicators;independent samples t-test - to compare the means between the two groups. The internal consistency between OCT and FA in visualising ME was evaluated by kappa, Kendall's tau-b. The level of significance of the zero hypothesis was set at $\mathrm{p}<0.05$ at $95 \%$ confidence interval.

Informed consent was obtained from the patients with uveitis and the healthy controls for participation in the study.

\section{RESULTS}

The mean age of the patients with uveitis was 43.7 $\pm 16.6 \mathrm{yrs}$ (mean $\pm \mathrm{SD}$ ) (range $20-78 \mathrm{yrs}$ ). Sixtysix patients were men $(56.4 \%)$ (mean age $42.8 \pm$ $16.5 \mathrm{yrs}$ ) and 51 were women $(43.6 \%)$ (mean age $44.8 \pm 16.9$ yrs). In $16(13.7 \%)$ the inflammation was in both eyes, and in the other 101 eyes $(86.3 \%)$ only in one of the eyes. 
The controls (160 volunteers, 160 eyes) had the mean age of $43.8 \pm 15.3$ yrs (mean \pm SD); 82 of these were men $(51.3 \%)$ at the mean age of 41.6 $\pm 15 \mathrm{yrs}$ and 78 - women $(48.7 \%)$ at the mean age of $46.2 \pm 15.5$ yrs.

Age had normal distribution in both groups: control (one-sample Kolmogorov-Smirnov test; $\mathrm{Z}=1.31 ; \mathrm{P}=0.07$ ) and patients with uveitis (onesample Kolmogorov-Smirnov test; $\mathrm{Z}=1.33 ; \mathrm{P}=$ 0.06 ). The groups were age matched (independent samples t-test: $\mathrm{t}=0.15 ; \mathrm{p}=0.88$ ) and sex-matched (independent samples $\mathrm{t}$-test; for men: $\mathrm{t}=0.45 ; \mathrm{p}$ $=0.65$; for women: $\mathrm{t}=0.45 ; \mathrm{p}=0.65$ ).

Table 1 presents the etiological distribution by anatomical location of uveitis in the patients.

The controls were used to build a system of normal values for the SD-OCT apparatus we used and differentiation of the normal retinal architectonic from early DME. DME was considered as present for eyes with uveitis where the retinal thickness exceeded the mean values of the sectors we mentioned earlier for both scan protocols MM6 and EMM5 in comparison with the results obtained in healthy controls (Table 2).

Table 3 presents the distribution of the eyes and the comparison between the two methods. In $27.8 \%$ (37 eyes) ME was detected by both imaging

Table 2. Macular thickness $(\mu \mathrm{m})$ in detecting diffuse macular edema

\begin{tabular}{cccc}
\hline Protocol & $\begin{array}{c}\text { CFP } \\
(\boldsymbol{\mu m})\end{array}$ & $\begin{array}{l}\text { CFT } \\
(\boldsymbol{\mu m})\end{array}$ & $\begin{array}{c}\text { TMT } \\
(\boldsymbol{\mu m})\end{array}$ \\
\hline MM6 & $>243$ & $>280$ & $>308$ \\
EMM5 & $>233$ & $>278$ & $>311$ \\
\hline
\end{tabular}

Legend: CFP - central fixation point; CFT - central foveal thickness; TMT - total macular thickness.

Table 1. Etiologic distribution of patients with uveitis by anatomical location of inflammatory process $(\mathrm{n}=231)$

\begin{tabular}{|c|c|c|c|c|c|}
\hline \multirow{3}{*}{ Etiology } & \multicolumn{4}{|c|}{ Location } & \multirow{3}{*}{$\begin{array}{c}\text { Total number of patients/ } \\
\text { eyes } \\
\text { n }\end{array}$} \\
\hline & \multicolumn{4}{|c|}{ Number of patients with } & \\
\hline & $\begin{array}{c}\mathbf{A U} \\
\mathbf{n}\end{array}$ & $\begin{array}{c}\text { IU } \\
\mathbf{n}\end{array}$ & $\begin{array}{c}\mathbf{P U} \\
\mathbf{n}\end{array}$ & $\begin{array}{c}\text { PANU } \\
\text { n }\end{array}$ & \\
\hline HLA B27(+) & 10 & - & - & - & $10 / 10$ \\
\hline Bekhterev's disease & 12 & - & - & - & $12 / 15$ \\
\hline Reiter syndrome & 5 & - & - & - & $5 / 5$ \\
\hline Psoriatic arthritis & 3 & - & - & - & $3 / 3$ \\
\hline JRA & 1 & - & - & - & $1 / 1$ \\
\hline RA & 1 & - & - & 1 & $2 / 3$ \\
\hline HSU & 2 & - & 1 & - & $3 / 3$ \\
\hline VZU & 7 & - & - & - & $7 / 7$ \\
\hline CMVU & - & - & - & 1 & $1 / 2$ \\
\hline Toxoplasmosis & 4 & 1 & 4 & 3 & $12 / 14$ \\
\hline Toxocariasis & - & - & 1 & 1 & $2 / 2$ \\
\hline $\mathrm{TB}$ & 2 & - & - & - & $2 / 3$ \\
\hline Sarcoidosis & - & - & 1 & - & $1 / 1$ \\
\hline Behcet's disease & - & - & - & 1 & $1 / 2$ \\
\hline MS & - & 1 & - & - & $1 / 1$ \\
\hline Sympathetic ophthalmia & - & - & - & 1 & $1 / 1$ \\
\hline White dot syndrome & - & - & 2 & - & $2 / 4$ \\
\hline Fuchs' uveitis & 1 & - & - & - & $1 / 2$ \\
\hline Posner-Schlossman Syndrome & 1 & - & - & - & $1 / 1$ \\
\hline Idiopathic uveitis & 36 & 6 & 1 & 6 & $49 / 55$ \\
\hline Total number of patients / eyes (n) & $85 / 90$ & $8 / 9$ & $10 / 13$ & $14 / 21$ & $117 / 133$ \\
\hline
\end{tabular}

Legend: JRA - juvenile rheumatoid arthritis; RA - rheumatoid arthritis; HSU - herpes simplex uveitis; VZU - varicella zoster uveitis; CMVU - cytomegalovirus uveitis; TB - tuberculosis; MS - multiple sclerosis; AU - anterior uveitis; IU intermediate uveitis; PU - posterior uveitis; PANU - panuveitis. 
Table 3. Coherence between OCT and FA in diagnosing ME in eyes with uveitis $(n=133)$

\begin{tabular}{lcc}
\hline \multirow{2}{*}{ OCT } & \multicolumn{2}{c}{ FA } \\
\cline { 2 - 3 } & Edema present & No edema \\
\hline Edema present & $37(27.8 \%)$ & $17(12.8 \%)$ \\
No edema & $3(2.3 \%)$ & $76(57.1 \%)$ \\
\hline
\end{tabular}

In 14 eyes both imaging methods found CME and in 20 eyes - DME (kappa $=0.68$; Kendall's tau-b $=0.69$ at $\mathrm{p}<0.001)$.

We analyse in greater detail the FA and OCT findings in 14 eyes with CME detected by the two imaging methods. In ten of the FA images CME has a petalloid-like pattern. In these cases the cystoid spaces on OCT are larger, centrally located

Table 4. Distribution of the different types of ME in eyes with uveitis, examined with OCT and FA $(n=133)$

\begin{tabular}{lcccc}
\hline \multirow{2}{*}{ OCT } & \multicolumn{5}{c}{ FA } \\
\cline { 2 - 5 } & No edema & DME & CME & SD \\
\hline No edema & $76(57.1 \%)$ & $3(2.3 \%)$ & - & - \\
DME & $15(11.3 \%)$ & $20(15 \%)$ & - & - \\
CME & - & $2(1.5 \%)$ & $14(10.5 \%)$ & $1(0.8 \%)$ \\
SD & $2(1.5 \%)$ & - & - & - \\
\hline
\end{tabular}

*Eyes with CME and eyes with CME in combination with SD of neuroepithelium are grouped together for better statistical comparability.

Legend: DME - diffuse macular edema; CME - cystoid macular edema; SD - serous retinal detachment of neuroepithelium.

modalities, while in $57.1 \%$ (76 eyes) OCT and FA found no pathological changes in the macula. In $2.3 \%$ (3 eyes with uveitis) FA detected ME that was not found on OCT while in $12.8 \%$ (17 eyes) of the cases ME was detected only on OCT. The agreement rate kappa between OCT and FA in detecting ME in uveitis was 0.68 . The coefficient of correlation, Kendall's tau-b was 0.69 indicating good consistency of both methods $(\mathrm{p}=0.001)$.

Table 4 presents in greater detail the types of ME detected on OCT and FA.

It is worth noting that in $11.3 \%$ of cases (15 eyes) OCT detected DME which FA failed to do (Fig. 1A). In the three eyes $(2.3 \%)$, in which ME was detected on FA only, and OCT found no abnormalities in the retinal thickness, the ME was also diffuse (Fig. 1B), that is, the greatest discrepancy in the diagnostic capabilities of the two methods lies in the detection of DME. In two of the eyes FA found no pathological changes in the retina, whereas OCT found SD of neuroepithelium in the macular area (Fig. 1C). FA found DME in two other eyes with uveitis included in the study, while OCT disclosed in them cystoid spaces in the retina (Fig. 1D). Serous detachment of the neuroepithelium in the macular area was observed in the late FA phases in 1 eye in which OCT, besides the SD of the neuroepithelium, detected microcystoid changes in the retina (Fig. 1E). and localized primarily in the outer retinal layers (outer plexiform, outer nuclear and more rarely in the inner plexiform layer) (Fig. 2A). In the other four eyes with uveitis, the CME as seen on FA shows a honeycomb-like pattern. OCT visualises the cysts mostly in the inner retinal layers (inner nuclear and plexiform) located paracentrally (Fig. 2B). In half of all 14 eyes with CME only OCT visualises simultaneous $\mathrm{SD}$ of the neuroepithelium in the macular area.

Depending on the FA and OCT findings the 133 eyes with uveitis were divided into four groups: no ME by both imaging methods, ME found on only one of the methods, and ME found on both OCT and FA. The distribution of FA and OCT findings by anatomical localization of uveitis is presented in Table 5 . In $15 \%$ of the cases (20 eyes) we found discrepancies between the two methods. The greatest mismatch between the OCT and FA imaging was found in the eyes with anterior uveitis in which ME was detected on OCT but not on FA.

\section{DISCUSSION}

There are few studies in the literature that compare the results obtained by OCT and FA in diagnosing macular edema in patients with uveitis. Our data suggest that there is good agreement between the FA and OCT findings (Kendall's tau-b - 0.69, p = 0.0001 ). One hundred and thirteen eyes out of a 

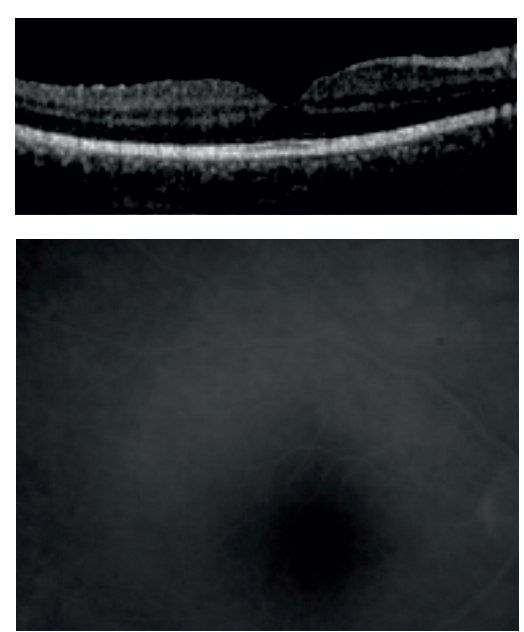

A.
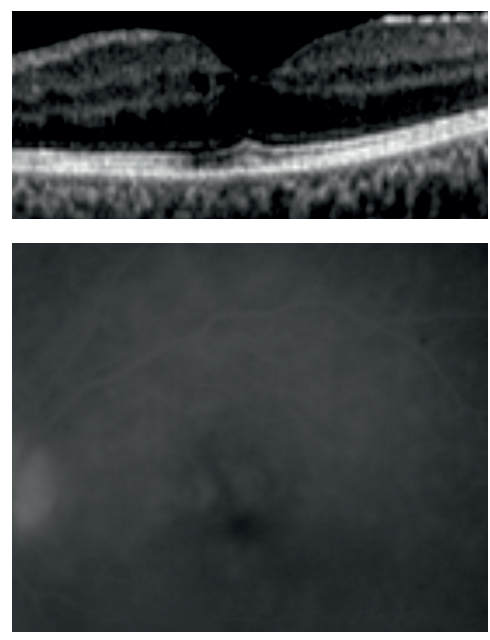

D.
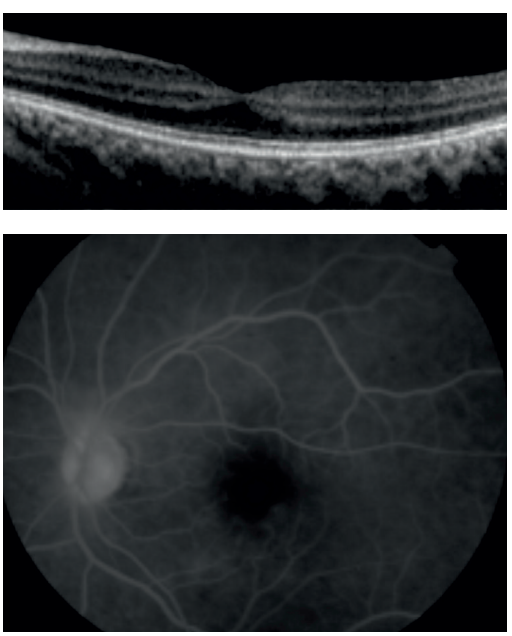

B.
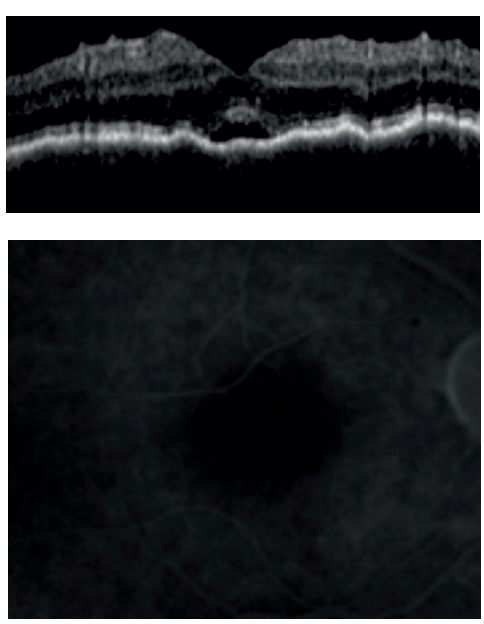

C.
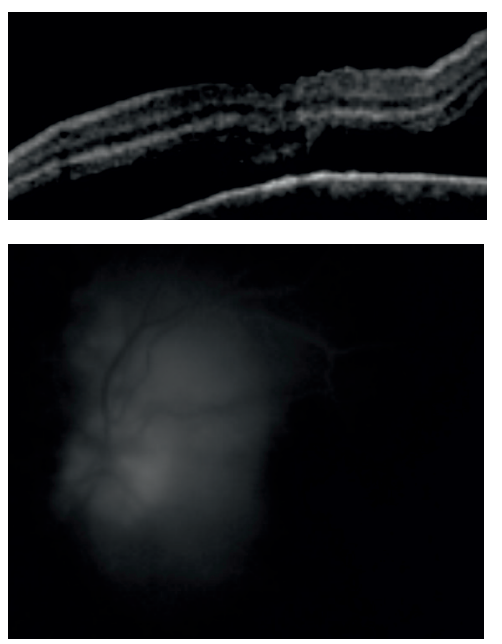

E.

Figure 1. Discrepancy between OCT and FA findings in patients with uveitis and macular edema. A) DME on OCT at normal FA finding; B) DME on FA at normal OCT finding; C) SD on OCT at normal FA finding; D) CME on OCT while FA visualises DME; E) late FA phases showing SD while OCT, in addition to SD, visualises microcysts.
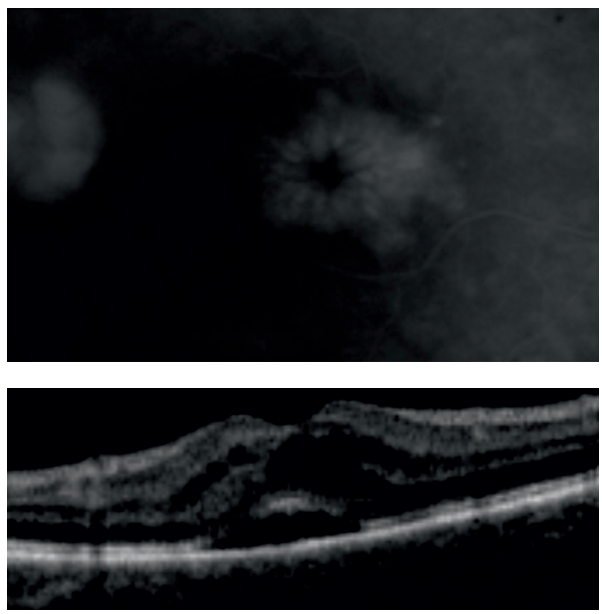

A.
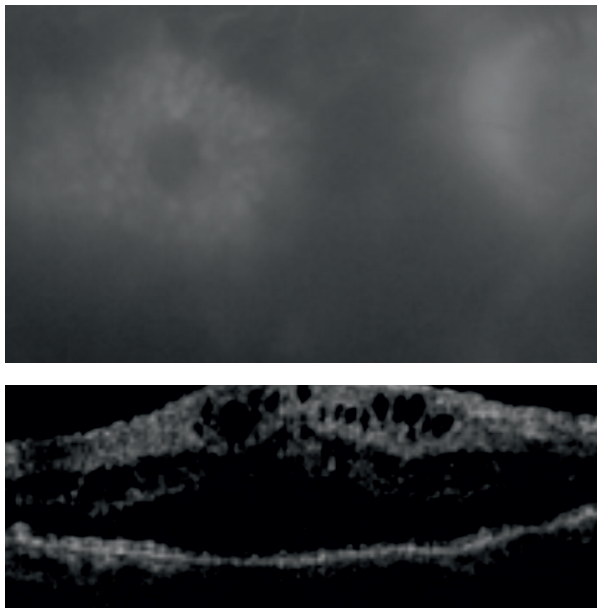

B.

Figure 2. CME in eyes with uveitis. A) FA visualises CME with the petalloid-like pattern, while OCT scans show cysts of various sizes located primarily in the outer retinal layers, as well as SD of the neuroepithelium from RPE. B) FA visualises CME of honeycomb-like pattern, while OCT scans show small and medium-sized cysts located mainly in the inner retinal layers, disrupted external retinal layers, and SD of the neuroepithelium from RPE. 
Table 5. Distribution of the different combinations of FA/OCT macular edema by anatomical location of uveitis $(n=133$ eyes $)$

\begin{tabular}{lcccc}
\hline \multirow{2}{*}{$\begin{array}{c}\text { Anatomical location of } \\
\text { uveitis }\end{array}$} & \multicolumn{4}{c}{ FA / OCT } \\
\cline { 2 - 5 } & FA - / OCT - & FA + / OCT - & FA - / OCT + & FA + / OCT + \\
\hline AU & $60(45.1 \%)$ & $1(0.8 \%)$ & $14(10.5 \%)$ & $16(12 \%)$ \\
$\mathrm{IU}$ & $5(3.8 \%)$ & - & - & $5(3.8 \%)$ \\
$\mathrm{PU}$ & $6(4.5 \%)$ & $1(0.8 \%)$ & - & $5(3.8 \%)$ \\
PANU & $4(3 \%)$ & $1(0.8 \%)$ & $3(2.3 \%)$ & $12(9 \%)$ \\
\hline
\end{tabular}

Legend: FA-/OCT - - no macular edema detected by both methods; FA+/OCT - - macular edema detected by FA but not by OCT; FA-/OCT + - macular edema detected by OCT but not by FA; FA+/ OCT + - macular edema detected by OCT and FA; AU - anterior uveitis; IU - intermediate uveitis; PU - posterior uveitis; PANU - panuveitis.

total of 133 eyes with uveitis had similar results on both OCT and FA. Similar data for the correlation between FA and OCT have been reported by Antcliff et al. (Kendall's $\tau-0.78, p=0.0001$ ). Their study included 121 eyes with uveitis (58 patients) and only in 13 cases there was a mismatch between OCT and FA findings. ${ }^{6}$ Tran et al. examined 129 eyes with inflammation of the uvea. The results for FA and OCT findings were similar in $86.8 \%$ of all cases. ${ }^{23}$

Brar et al. studied macular edema in patients with diabetes and uveitis after vein occlusion, epiretinal membranes and pseudophakic edema and found strong correlation between FA and OCT (Spectralis) findings. ${ }^{1}$ They reported that CME detected on FA can always be detected on OCT, while a diffuse FA leakage is seen on OCT as either diffuse or cystoid leakage. Our study corroborates these conclusions. In all cases we found CME on FA it was confirmed on OCT. Jittpoonkuson et al. studied patients with CME with different etiology. ${ }^{24}$ They found 4 cases of uveitis in a total of 85 eyes ( 85 patients). These researchers found the greatest discrepancy between OCT and FA findings in the eyes with age-related macular degeneration and diabetic retinopathy. In their study CME was detected only on OCT in $33.3 \%$ of all cases, while in uveitic eyes CME was found by both FA and OCT.

In the present study, DME was detected on FA in two eyes with uveitis, while OCT found only microcystoid spaces. The diffuse angiographic macular edema can be seen in some cases as microcystoid on SD-OCT because of the higher resolution of SD-OCT $(5-7 \mu \mathrm{m})$ compared to FA. ${ }^{1}$ CME begins at first in the form of small cystoid spaces in the outer plexiform layer that are seen on FA at first as diffuse leakage. ${ }^{9}$

We found serous detachment of the neuroepithelium from RPE on OCT in 9 eyes, which was confirmed by FA only in one of the cases. Our results are consistent with the results reported by Tran et al. These researchers found SD in 9 eyes with uveitis using OCT that was not detected on FA. ${ }^{23}$ Yeung et al. studied 58 eyes with diabetic retinopathy and detected SD of the neuroepithelium in $11(18.6 \%)$ of them on SD-OCT. ${ }^{9}$ These changes in the eyes were not confirmed by a specific FA finding. Reports in the literature have indicated that subretinal fluid can be seen only on OCT, although late FA phases, in some cases, may show edema. $^{25,26}$

We observed the greatest discrepancy between FA and OCT findings in the detection of DME. In 15 eyes $(11.3 \%)$ we found DME detected only on OCT. DME is thought to arise as a result of metabolic stress, leading to cellular dysfunction and intracellular accumulation of fluid. As a consequence, retinal thickness increases without undergoing any cystoid changes and any vascular leakage..$^{23,27,28}$ Other researchers suggest that DME is the result of extracellular accumulation of fluid in the macular area, which has not yet been evacuated. If the leak through the vascular walls has stopped, FA will not show ME, but the edema will be detected on OCT. ${ }^{6,28}$ Most of the studies in this respect, with patients with uveitis, use timedomain OCT apparatus investigating the macular thickness. This may account to some extent for the fact that these researchers report much smaller number of cases than we have of ME detected on OCT but not on FA.

The analysis we made suggests that by anatomical position of uveitis the greatest discrepancy between FA and OCT findings occurs in patients with anterior uveitis. In 14 eyes with anterior uveitis, macular edema was detected only on OCT. We found no comments on this finding in the 
available ophthalmologic literature. We think that in AU patients DME is more often detected on OCT and absence of edema on FA because of the reasons we mentioned earlier and also as a result of the shorter vascular leakage (the inflammation affects the anterior parts of the uvea).

Our results indicate that ME is detected on FA but not on OCT in $2.3 \%$ of all cases. Similar data are reported by Brar et al. ${ }^{1}$ They detected ME on FA and found no changes on OCT in $3.73 \%$ of their cases. Our results are consistent also with the results reported by Ancliff et al. ${ }^{6}$ These researchers detected focal ME on FA in 3 eyes with uveitis (in stage 1 by the classification of Yannuzzi et al. ${ }^{29}$ ) but it did not visualise on OCT. In patients with weak focal leakage, the central retinal thickness may be seen as normal on OCT. Studies in the available literature on the subject suggest that in such cases the fluid in the retina is in very small quantity, which makes the morphologic changes impossible to visualise. ${ }^{1,30-32}$ This may account for the fact that in all eyes we found macular edema only on FA, it was a diffuse edema. On the other hand, in intraocular inflammatory disorders the blood retinal barrier breaks early when the compensating mechanisms are still efficient enough. ${ }^{23}$ In such cases, FA turns out to be a more sensitive method than OCT in detecting ME. ${ }^{1,28}$ The results reported by Ossewaarde-van Norel et al. are not consistent with our results. ${ }^{28}$ They examined 120 eyes (78 patients) with uveitic ME and found mismatches between FA and OCT findings in $46 \%$ of all cases. In 34 eyes (30\%) ME was detected on FA but not on OCT. This difference between the results reported by Ossewaarde-van Norel et al. and our own results is due to several factors. They used TD-OCT (Stratus) to diagnose ME. The TD-OCT apparatus being of lower resolution is the reason they did not detect the microcystoid spaces in the perifoveal area which however can be visualised on SD-OCT. Also the study included patients with a long history of uveitis. The long term leakage in these patients was most probably combined with atrophy and decrease of the retinal thickness. Patients with atrophic changes in the macula and inactive uveitis were excluded from our study.

The present study is not without any limitations. First, the classification of macular leakage on FA is not accurate. It is not possible to make a precise grading of the severity of the edema using a numeric value - the assessment is to some extent subjective depending on the skills and experience of the researcher. On the other hand, the concentration of fluorescein decreases in the various FA phases, and there is no linear relationship between the quantity of fluorescein and fluorescence intensity. ${ }^{28} \mathrm{We}$ have grouped together focal $\mathrm{ME}$ and diffuse $\mathrm{ME}$ to achieve better comparability with the results from OCT, which, however, is not quite correct. Some studies use the 5-point FA classification of ME suggested by Yannuzzi et al. ${ }^{29}$ However, it does not match the OCT classification of macular edema.

Our results show good agreement between SD-OCT and FA findings when ME is found in patients with uveitis. The two methods are highly sensitive, but is quite likely that macular edema may be missed if these methods are used independently. SD-OCT is the more informative and reliable method in patients with the DME. FA and OCT are used complementary in diagnosing ME in patients with intraocular inflammatory diseases. Each of these methods reveals different aspects of the pathogenic features of uveitis.

OCT is increasingly required in ophthalmic practice as a method taking less time for preparation and execution, absence of systemic risks, possibility of quantification of retinal thickness, as well as good reproducibility and comparability of the results.

\section{REFERENCES}

1. Brar M, Yuson R, Kozac I, et al. Correlation between morphologic features on spectral-domain optical coherence tomography and angiographic leakage patterns in macular edema. Retina, 2010;30:383-9.

2. Marmor MF. Mechanisms of fluid accumulation in retinal edema. Doc Ophthalmol, 1999;97:239-49.

3. Sepah YJ, Hatef E, Colantuoni E, et al. Macular sensitivity and fixation patterns in normal eyes and eyes with uveitis with and without macular edema. J Ophthal Inflamm Infect, 2012;2 (2):65-73.

4. Lardenoye CW, Kooij B, Rothova A. Impact of macular edema on visual acuity in uveitis. Ophthalmology, 2006;113:1446-9.

5. Iannety L, Accorinti M, Liverani M, et al. Optical coherence tomography for classification and clinical evaluation of macular edema in patients with uveitis. Ocular Immunology and Inflammation, 2008;16: 155-160.

6. Antcliff RJ, Stanford MR, Chauhan DS, et al. Comparison between optical coherence tomography and fundus fluorescein angiography for the detection of cystoid macular edema in patients with uveitis. Ophthalmology, 2000;107:593-9.

7. Kang SW, Park CY, Ham AD. The correlation between fluorescein angiography and optical coherence 
tomography features in clinically significant diabetic macular edema. Am J Ophthalmol, 2004;137:313-22.

8. Schaudig U, Scol F, Lerche RS, Richard G. Optical coherence tomography for macular edema. Classificationq quantitative assessment, and rational usage in the clinical practice. Ophthalmology, 2004;101:785-.

9. Yeung L, Lima VS, Garcia PC. Correlation between Spectral Domain Optical Coherence Tomography Findings and Fluorescein Angiography Patterns in Diabetic Macular Edema. Ophthalmology, 2009;116:1158-67.

10.Chang A, Spaide RF, Yannuzzi LA. Postsurgical cystoid macular edema. Retina, 1999;1: 239-55.

11. Markomichelakis NN, Halkiadakis I, Pantelia E, et al. Patterns of macular oedema in patients with uveitis: qualitative and quantitative assessment using optical coherence tomography. Ophthalmology, 2004;111: 946-53.

12. Nussenblatt RB, Scott MW. Uveitis fundamentals and clinical practice. 4th ed. ISPN: 978-1-4377-0677-3. Elsevier Inc, 2010.

13. Apostolopoulos MN, Koutsandrea CN, Moschos $\mathrm{MN}$, et al. Evaluation of successful macular hole surgery by optical coherence tomography and multifocal electroretinogrphy. Am J Ophthalmology, 2002;134:667-74.

14. Theodossiadis GP, Theodossiadis PG. Optical coherence tomography in optic disk pit maculopathy treated by macular buckling procedure. Am J Ophthalmol, 2001;132:184-90.

15. Theodossiadis PG, Kollia AK, Gogas P, et al. Retinal disorders in preeclampsia studied with optical coherence tomography. Am J Ophthalmology, 2002;133:707-9.

16. Sivaprasad S, Ikeji F, Hing W, Lightman S. Tomographic assessment of therapeutic response to uveitic macular edema. Clinical and Experimental Ophthalmology, 2007;35:719-23.

17. Roesel M, Heimes B, Heinz C, et al. Comparison of retinal thickness and fundus - related microperimetry with visual acuity in uveitic macular edema. Acta Ophthalmol, 2011;89:533-7.

18. Duan XR, Liang YB, Friedman DS, et al. Normal macular thickness measurement using optical coherence tomography in healthy eyes of adult Chinese person: the Handan eye study. Ophthalmology, 2010;117:1585-94.

19. Wollstein G, Ishikawa H, Wang J, et al. Comparison of three optical coherence tomography scanning areas for detection of glaucomatous damage. Am J Ophthalmol, 2005;139(1):39-43.
20.Hee MR, Puliafito CA, Duker JS, et al. Topography of diabetic macular edema with optical coherence tomography. Ophthalmology, 1998;105(2):360-370.

21. Massin P, Erginay A, Haouchine B, et al. Retinal thickness in healthy and diabetic subjects measured using optical coherence tomography mapping software. Eur J Ophthalmol, 2002;12:102-8.

22. Clarc TM. Retinal Photography and Angiography via Film and Digital Imaging Techniques. In:Arevalo JF. Retinal Angiography and Optical Coherence Tomography. New York:Springer;2009:3-26.

23. Tran TH, Smet MD, Bodaghy B, et al. Uveitic macular edema:correlation between optical coherence tomography patterns with visual acuity and fluorescein angiography. Br J Ophthalmol, 2008;92 (7):922-7.

24. Jittpoonkuson T, Garcia PM, Rosen RB. Correlation between fluorescein angiography and spectraldomain optical coherence tomography in the diagnosis of cystoid macular edema. Br J Ophthalmol, 2010;94:1197-200.

25. Koleva-Georgieva D. Clinical assessment of diabetic macular edema by spectral-domain optical coherence tomography. [Dissertation] medical University, Plovdiv, 2011 (Bulgarian).

26. Bolz M, Ritter M, Schnaider M, et al. A systematic correlation of angiography and high-resolution optical coherence tomography in diabetic macular edema. Ophthalmology, 2009;116:66-72.

27. Freeman G, Matos K, Pavesio CE. Cystoid macular oedema in uveitis:an unsolved problem. Eye, 2001; 15(1):12-17.

28. Ossewaarde-van Norel J, Camfferman LS, Rothova AA. Discrepancies between fluorescein angiography and optical coherence tomography in macular edema in uveitis. Am J Ophthalmol, 2012;154 (2):233-9.

29. Yannuzzi LA, Rohrer KT, Tindel LJ, et al. Fluorescein angiography complication survey. Ophthalmology, 1986;93:611-7.

30. Kozak I, Morrison VL, Clark TM, et al. Discrepancy between fluorescein angiography and optical coherence tomography in detection of macular disease. Retina, 2008;28 (4):538-44.

31. Ouyang Y, Keane PA, Sadda SR, Walsh AC. Detection of cystoid macular edema with threedimensional optical coherence tomography versus fluorescein angiography. Invest Ophthalmol Vis Sci, 2010;51:5213-8.

32. Soliman W, Sander B, Hasler PW, Larsen M. Correlation between intraretinal changes in diabetic macular oedema seen in fluorescein angiography and optical coherence tomography. Acta Ophthalmol, 2008;86 (1):34-9. 